\title{
Price Controls in the Postal Sector: A Welfare Analysis of Alternative Control Structures
}

\author{
Ph. De Donder, H. Cremer \\ University of Toulouse (IDEI and GREMAQ) \\ P. Dudley, F. Rodriguez $\quad$ (Royal Mail Group) ${ }^{1}$ \\ February 14, 2007 \\ Prepared for the fourth Toulouse Conference on Postal \\ Economics
}

\footnotetext{
${ }^{1}$ The analysis contained in this paper reflects the views of the authors and may not necessarily be those of Royal Mail Group.
} 


\section{Introduction}

In setting price controls, regulators are likely to have a number of duties and objectives. Typically, at the centre of these requirements for the postal sector is likely to be a duty or objective to ensure the continuing provision of universal postal service implying ubiquity of provision and geographical uniformity of tariffs for at least single piece mail items. Continuing provision implies also setting a price control which ensures the financial viability of an (efficient) universal service provider (USP). The optimal structure for a price control reflecting an objective of maximisation of allocative efficiency is that of a global price cap (GPC) (Billette et al, 2003). But regulators may have other objectives which may be linked to their statutory duties. These may include the promotion of competitive entry into the postal market and a desire to keep the prices of at least single piece mail low for equity and social reasons. For example, Panzar (2004) has suggested very convincingly that regulators may wish to minimize the (highly visible and politically sensitive) single-piece price while allowing the USP to break even. In seeking to achieve a balance between these objectives, regulators may make trade-offs and adopt rules that are non-optimal compared with the benchmark of the GPC.

In this paper, we examine some of these issues by comparing the results of the second best (Ramsey) welfare-maximising program to those obtained with alternative procedures that might be adopted by regulators in seeking to achieve also other objectives. The focus of our paper is therefore on the structure of price controls in the postal sector and the implications and impacts of regulators seeking to satisfy a range of objectives or duties including allocative efficiency, equity and the promotion of entry while seeking to ensure continuing provision of universal service. We do not try to model explicitly the regulator's objectives other than welfare-maximisation and to derive from them the optimal price control mechanisms that should be imposed on the USP. One reason why we do not follow this normative approach is that we do not know how regulators weigh the different objectives that they may pursue simultaneously. The approach this paper takes is more positive, starting from price control mechanisms that are used in practice, and studying the consequences of different policies and procedures in terms of price structure, volume and welfare levels and other issues such as the continuing financial viability of the USP. Doing this requires not only to study these procedures analytically, but also to resort to numerical simulations of a calibrated model.

In our model, the USP offers both a single piece product and a business mail product. A number of entrants, acting as a competitive fringe, offer a bulk mail product that is an (imperfect) substitute to the bulk mail offered by the USP. This setting builds on De Donder et al. (2006a), but is richer 
in three dimensions. First, we assume two delivery areas (urban and rural) instead of one, and impose the condition that the USP single-piece letter price be the same in both delivery areas (while bulk mail prices may be differentiated across areas). Second and more importantly, we assume that the USP sells access to its (rural and/or urban) delivery areas to the entrants. In other words, the USP sells an intermediate good as well as two final goods. The entrants choose whether to deliver themselves in a given area or whether to access the USP's delivery network in an area. Third, the presence of access products as well as final products allows us to study a wider variety of price control procedures than is contained in De Donder et al. (2006a).

The paper proceeds as follows. Our model is set out further in section 2 . Section 3 studies analytically the two price control procedures we concentrate on: a global price cap/Ramsey program with a minimum difference between bulk mail and access prices, and a price cap control with two baskets of mail products. Section 4 calibrates the model while section 5 presents the numerical results obtained with these price control mechanisms, depending on whether access is available or not, and looks at their robustness. Section 6 studies the introduction of a universal service fund financed by taxing the entrants's output. Section 7 concludes.

\section{The model}

There are two kinds of postal operators: the USP and a number of entrants. The USP offers two products (single-piece mail and bulk mail) to two delivery areas (urban and rural). The USP is required to post a single price, denoted by $q$, for single-piece mail delivered to either area. We denote the demand function for single-piece mail delivered to area $i=U, R$ by $x_{i}(q)$.

The entrants offer a bulk mail product for urban and rural delivery. Entrants offer an identical service to each other, and behave like a competitive fringe. Both bulk mail products (the one offered by the USP and by the entrants) are imperfect substitutes in any given area. The demand in one area does not depend on the price charged for delivery to the other area. The demand function for USP bulk mail delivered in area $i=U, R$ is denoted by $y_{i}^{I}\left(p_{i}^{I}, p_{i}^{E}\right)$ with $p_{i}^{I}$ the USP price and $p_{i}^{E}$ the entrant's price, and with $\partial y_{i}^{I}(.) / \partial p_{i}^{I}<0$ and $\partial y_{i}^{I}(.) / \partial p_{i}^{E}>0$. Similarly, the demand for the entrants's bulk mail product is given by $y_{i}^{E}\left(p_{i}^{I}, p_{i}^{E}\right)$ with $\partial y_{i}^{E}(.) / \partial p_{i}^{E}<0$ and $\partial y_{i}^{E}(.) / \partial p_{i}^{I}>0$.

The demand functions are derived from the maximization of net user surplus, with gross user surplus given by $V_{i}\left(x_{i}\right)$ for single-piece mail sent to area $i$ and $U_{i}\left(y_{i}^{I}, y_{i}^{E}\right)$ for bulk mail sent to area $i$. As is standard in 
this literature, we use surplus as a measure of welfare for firms buying mail products (see Billette et al. (2003) for instance).

The postal activity is divided in two segments: the upstream segment is composed of collection, sorting and transportation, while the downstream segment is delivery. Each segment has a constant marginal cost. Upstream marginal costs for the USP are $c_{x}$ for the single-piece good and $c^{I}$ for the bulk mail product, with $c_{x}>c^{I}$. We assume the same USP delivery cost for single-piece mail and for bulk mail, which we denote by $d_{i}^{I}$ for delivery to area $i=U, R$, with $d_{R}^{I}>d_{U}^{I}$. Similarly for the entrants, we have that rural delivery of bulk mail, $d_{R}^{E}$ is more expensive than urban delivery, $d_{U}^{E}$.

In addition to selling the two end-to-end (E2E) goods (i.e. the goods that use both the upstream and downstream USP segments), the USP also sells entrants access to its delivery network in both areas for a unit price of $a_{i}$, $i=U, R$, which we call the access charge. We assume that the selling of access to both areas is mandatory and has to be offered by the USP. Entrants can choose whether to bypass and deliver through their own network or to access the USP delivery network in each area. Entrants will choose the cheapest way to proceed and so access the USP delivery network in area $i=U, R$ if $d_{i}^{E}>a_{i}$ and bypass otherwise.

The universal service obligations translate into a fixed cost $F$ for the USP. The entrants' price is

$$
p_{i}^{E}=c^{E}+\min \left(a_{i}, d_{i}^{E}\right), i=U, R
$$

\section{Price control procedures}

As noted in the introduction, in practice regulators have several duties and objectives to fulfil when setting price controls in addition to ensuring the provision of the universal service, such as promoting competition and entry to the sector and equity. The associated policy procedures may include multiple baskets rather than a global control; accompanying cost allocation rules to divide fixed costs between products inside and outside of the price control; and constraints on individual product prices and the relationship between prices. ${ }^{1}$ In this section, we examine analytically the effect of two such procedures, namely, setting a minimum price difference between bulk mail prices and access prices which can be used as a way to promote and maintain entry into the market; and multiple baskets which when linked to a cost allocation rule such as EPMU can be viewed as another way to constrain prices and

\footnotetext{
${ }^{1}$ For example, in the UK policy procedures of this type are used in controlling the universal service provider's prices (Postal Services Commission, 2006).
} 
may act to support equity objectives and/or promote entry. We first develop our analysis without allowing for the possibility of bypass before showing the analytical impact of its availability in section 3.3.

\subsection{Ramsey prices with constraint on margin between E2E and access price}

In this subsection, we study the procedure where a minimum difference between bulk mail and access prices is added to the classical Ramsey problem. Our objective is to analyze the impact of this constraint on the optimal prices. We show in an appendix that these prices can be decentralized using a suitable global price cap - i.e., a price cap that includes the access products sold by the regulated operator.

The Ramsey, second best optimal prices maximize total welfare (net user surplus plus postal firms' profits) subject to the USP breaking even. They are the solution to

$$
\begin{aligned}
\max _{q, p_{U}^{I}, p_{R}^{I}, a_{U}, a_{R}} W= & \sum_{i=U, R} V_{i}\left(x_{i}\right)+\sum_{i=U, R} U_{i}\left(y_{i}^{I}, y_{i}^{E}\right) \\
& -\left(x_{U}+x_{R}\right) q-p_{U}^{I} y_{U}^{I}-p_{R}^{I} y_{R}^{I}-p_{U}^{E} y_{U}^{E}-p_{R}^{E} y_{R}^{E} \\
& +(1+\lambda)\left[\left(q-c_{x}-d_{x U}\right) x_{U}+\left(q-c_{x}-d_{x R}\right) x_{R}\right. \\
& +\left(p_{U}^{I}-c^{I}-d_{U}^{I}\right) y_{U}^{I}+\left(p_{R}^{I}-c^{I}-d_{R}^{I}\right) y_{R}^{I} \\
& \left.+\left(a_{U}-d_{U}^{I}\right) y_{U}^{E}+\left(a_{R}-d_{R}^{I}\right) y_{R}^{E}-F\right]
\end{aligned}
$$

where $\lambda$ denotes the Lagrange multiplier of the USP profit constraint and where the arguments of the demand functions have been omitted.

To this optimisation program, we add a constraint on the minimum difference between the access charge and the USP bulk mail price on both delivery areas:

$$
p_{i}^{I}-a_{i} \geq m_{i}, i=U, R
$$

with this minimum difference $m_{i}$ chosen by the regulator. We assign the Lagrange multipliers $\eta_{i}, i=U, R$ to these constraints.

We obtain the following first order conditions, for $q, p_{i}^{I}$ and $a_{i} \quad(i=U, R)$ respectively: 


$$
\begin{gathered}
-\left(x_{U}+x_{R}\right)+(1+\lambda)\left[x_{U}+x_{R}+\left(q-c_{x}-d_{x U}\right) \frac{\partial x_{U}}{\partial q}+\left(q-c-d_{x R}\right) \frac{\partial x_{R}}{\partial q}\right]=0 \\
-y_{i}^{I}+(1+\lambda)\left[y_{i}^{I}+\left(p_{i}^{I}-c^{I}-d_{i}^{I}\right) \frac{\partial y_{i}^{I}}{\partial p_{i}^{I}}+\left(a_{i}-d_{i}^{I}\right) \frac{\partial y_{i}^{E}}{\partial p_{i}^{I}}\right]+\eta_{i}=0 \\
-y_{i}^{E}+(1+\lambda)\left[y_{i}^{E}+\left(p_{i}^{I}-c^{I}-d_{i}^{I}\right) \frac{\partial y_{i}^{I}}{\partial p_{i}^{E}}+\left(a_{i}-d_{i}^{I}\right) \frac{\partial y_{i}^{E}}{\partial p_{i}^{E}}\right]-\eta_{i}=0
\end{gathered}
$$

To interpret these conditions, we first assume that the margin constraints (2) are not binding at the optimum (i.e., $\eta_{i}=0$ ). If the budget constraint is not binding either (i.e., $\lambda=0$ ), we obtain marginal cost pricing for bulk mail as well as for access. The single-piece price is then given by a convex combination of the marginal costs in both delivery areas.

However, given the fixed cost, the USP does not break even with marginal cost pricing so that $\lambda$ has to be strictly positive at the optimum. Still assuming that $\eta_{i}=0$ and solving separately for $a_{i}$, we obtain

$$
a_{i}=d_{i}^{I}+\left(p_{i}^{I}-c^{I}-d_{i}^{I}\right) \frac{-\frac{\partial y_{i}^{I}}{\partial p_{i}^{E}}}{\frac{\partial y_{i}^{E}}{\partial p_{i}^{E}}}+\frac{\lambda}{1+\lambda} \frac{y_{i}^{E}}{\frac{\partial y_{i}^{E}}{\partial p_{i}^{E}}},
$$

where the optimal access charge is the sum of the delivery cost, a foregone profit term factored by the displacement ratio ${ }^{2}$ and a Ramsey term. If we go further and solve simultaneously for $a_{i}$ and $p_{i}^{I}$, we obtain

$$
\begin{gathered}
a_{i}^{*}=d_{i}^{I}+\frac{\lambda}{1+\lambda} \frac{y_{i}^{E} \frac{\partial y_{i}^{I}}{\partial p_{i}^{I}}-y_{i}^{I} \frac{\partial y_{i}^{I}}{\partial p_{i}^{I}} \frac{\partial y_{i}^{I}}{\partial p_{i}^{E}}+\frac{\partial y_{i}^{E}}{\partial p_{i}^{E}} \frac{\partial y_{i}^{I}}{\partial p_{i}^{I}},}{p_{i}^{I *}=c^{I}+d_{i}^{I}+\frac{\lambda}{1+\lambda} \frac{y_{i}^{I} \frac{\partial y_{i}^{E}}{\partial p_{i}^{E}}-y_{i}^{E} \frac{\partial y_{i}^{E}}{\partial p_{i}^{I}}}{\partial y_{i}^{E}} \frac{\partial y_{i}^{I}}{\partial p_{i}^{E}}+\frac{\partial y_{i}^{E}}{\partial p_{i}^{E}} \frac{\partial y_{i}^{I}}{\partial p_{i}^{I}}},
\end{gathered}
$$

where both prices are expressed as the sum of marginal cost and of a Ramsey term.

We now assume that the margin constraint is binding in area $i$. In that case, it will prove easier to replace $p_{i}^{I}$ by $a_{i}+m_{i}$ in the modified Ramsey problem rather than using the Lagrange multiplier method. While the first

\footnotetext{
${ }^{2}$ See Armstrong (2002) and De Donder (2006).
} 
order condition for $q$ is unchanged, the condition for the optimal access charge becomes

$$
\begin{aligned}
& -\left(y_{i}^{I}+y_{i}^{E}\right)+(1+\lambda)\left[y_{i}^{I}+y_{i}^{E}+\left(a_{i}+m_{i}-c^{I}-d_{i}^{I}\right)\left(\frac{\partial y_{i}^{I}}{\partial p_{i}^{I}}+\frac{\partial y_{i}^{I}}{\partial p_{i}^{E}}\right)\right. \\
& \left.+\left(a_{i}-d_{i}^{I}\right)\left(\frac{\partial y_{i}^{E}}{\partial p_{i}^{I}}+\frac{\partial y_{i}^{E}}{\partial p_{i}^{E}}\right)\right]=0,
\end{aligned}
$$

because increasing the access charge also increases the bulk mail price when the constraint (2) is binding.

We start as previously by assuming that $\lambda=0$, in which case (9) simplifies to

$$
a_{i}=d_{i}^{I}+\left(c^{I}-m_{i}\right) \frac{\frac{\partial y_{i}^{I}}{\partial p_{i}^{I}}+\frac{\partial y_{i}^{I}}{\partial p_{i}^{E}}}{\frac{\partial y_{i}^{I}}{\partial p_{i}^{I}}+\frac{\partial y_{i}^{I}}{\partial p_{i}^{E}}+\frac{\partial y_{i}^{E}}{\partial p_{i}^{I}}+\frac{\partial y_{i}^{E}}{\partial p_{i}^{E}}} .
$$

Recall that the Ramsey prices when $\lambda=0$ and in the absence of margin constraint are equal to marginal cost, i.e. $a_{i}=d_{i}^{I}$ and $p_{i}^{I}=c^{I}+d_{i}^{I}$ so that $p_{i}^{I}-a_{i}=c^{I}$. Since we assume that the margin constraint is binding, we have that $c^{I}<m_{i}$-i.e., the first part of the second term in (10) is negative. As for the second part of the second term, it is positive in the usual case where direct price effects on demands are larger (in absolute value) than cross price effects - i.e., $\partial y_{i}^{I} / \partial p_{i}^{I}+\partial y_{i}^{I} / \partial p_{i}^{E}<0$ and $\partial y_{i}^{E} / \partial p_{i}^{I}+\partial y_{i}^{E} / \partial p_{i}^{E}<0$. We then obtain that $a_{i}<d_{i}^{I}$ - i.e., that access charges are smaller than delivery cost when the margin constraint is binding. The intuition for this result is straightforward: in the absence of margin constraint and of (binding) profit constraint, the optimal access charge equals the USP delivery cost. The margin constraint is binding if and only if the minimum margin $m_{i}$ is larger than the USP collection cost $c^{I}$. In that case, the optimal access charge decreases (compared to the situation without binding margin constraint) and becomes smaller than the USP delivery cost, while the optimal bulk mail price increases.

However, the presence of fixed costs prevents the USP from breaking even with these prices. The value of the Lagrange multiplier of the profit constraint is then positive at equilibrium. We obtain that

$$
a_{i}=d_{i}^{I}+\left(c^{I}-m_{i}\right) \frac{\frac{\partial y_{i}^{I}}{\partial p_{i}^{I}}+\frac{\partial y_{i}^{I}}{\partial p_{i}^{E}}}{\frac{\partial y_{i}^{I}}{\partial p_{i}^{I}}+\frac{\partial y_{i}^{I}}{\partial p_{i}^{E}}+\frac{\partial y_{i}^{E}}{\partial p_{i}^{I}}+\frac{\partial y_{i}^{E}}{\partial p_{i}^{E}}}+\lambda \frac{-\left(y_{i}^{I}+y_{i}^{E}\right)}{\frac{\partial y_{i}^{I}}{\partial p_{i}^{I}}+\frac{\partial y_{i}^{I}}{\partial p_{i}^{E}}+\frac{\partial y_{i}^{E}}{\partial p_{i}^{I}}+\frac{\partial y_{i}^{E}}{\partial p_{i}^{E}}},
$$

where the third term plays the role of a Ramsey term, calling for a mark-up that is inversely proportional to the sensitivity of the bulk mail demands to prices. Given the addition of this term, the comparison with the optimal 
$a_{i}$ under the classical Ramsey problem is in general ambiguous. We will then use numerical simulations to gain insights into possible direction of this comparison.

\subsection{Two separate price cap constraints}

We now consider a case where the regulator imposes more than one price cap constraint on the goods covered by these price caps. We treat here the "two basket" case where the regulator imposes separate price cap constraints on single piece and on bulk mail products. We assume that the access products belong to the bulk mail basket (since they are closer substitutes to the bulk mail products than to the single-piece mail), but it is easy to modify the analysis presented here to other cases.

We assume that the regulator sets the proportion of fixed costs to be recovered inside each basket. ${ }^{3}$ We denote by $\alpha$ the proportion of fixed costs that has to be recovered by the basket containing single piece mail. The problem for the USP is then two fold. First, for this basket, the USP looks for the (smallest) value of $q$ such that

$$
\left(q-c_{x}-d_{x U}\right) x_{U}+\left(q-c_{x}-d_{x R}\right) x_{R}=\alpha F .
$$

Second, for the basket containing bulk mail, the USP solves

$$
\begin{aligned}
& \max _{p_{U}^{I}, p_{R}^{I}, a_{U}, a_{R}}\left(p_{U}^{I}-c^{I}-d_{U}^{I}\right) y_{U}^{I}+\left(p_{R}^{I}-c^{I}-d_{R}^{I}\right) y_{R}^{I} \\
& +\left(a_{U}-d_{U}^{I}\right) y_{U}^{E}+\left(a_{R}-d_{R}^{I}\right) y_{R}^{E} \\
& -\mu\left[n_{U}^{I} p_{U}^{I}+n_{R}^{I} p_{R}^{I}+n_{a U} a_{U}+n_{a R} a_{R}-\bar{p}\right]
\end{aligned}
$$

where $\mu$ denotes the Lagrange multiplier of the price cap constraint in this basket.

We assume in what follows that, once the regulator has chosen the value of $\alpha,{ }^{4}$ it sets the weights and average price in the bulk mail basket at their optimal, welfare-maximizing levels given this constraint. In other words, the price cap for the bulk mail basket is chosen by the regulator in order to decentralize the optimal, third-best Ramsey prices for the bulk mail products - i.e., the prices that maximize total welfare subject to the constraints that the USP globally breaks even and that the proportion of the fixed costs covered by single piece mail is $\alpha$. This means that, although $\alpha$ does not

\footnotetext{
${ }^{3}$ This is also the approach adopted in De Donder et al. (2006b).

${ }^{4}$ In choosing this value the regulator may follow an accounting rule such as fully distributed costs.
} 
appear in (12), the value of $\alpha$ is used by the regulator when choosing the values of $n_{i}^{I}, n_{a i}$ and $\bar{p}$.

Let us consider further the choice by the regulator of the proportion $\alpha$ and denote by $\alpha^{*}$ the proportion of the fixed cost recovered by the singlepiece product in the classical Ramsey program (1) (or equivalently, under the optimal global price cap - see appendix, equation (14)). It is clear that, if the regulator imposes two separate price caps but chooses $\alpha=\alpha^{*}$, we end up with the optimal second best situation. If $\alpha$ is set below $\alpha^{*}$, this will drive the single-piece mail price down and the other prices up, compared to their optimal second-best levels. Formally, the formulas for the equilibrium competitive prices are still given by equations (7) and (8), but the value of $\lambda$ is now larger than in the global Ramsey problem: by imposing that a higherthan-optimal share of the fixed costs be covered by the access and bulk mail products, the regulator increases the tightness of the budget constraint for this group of products, which in turn increases the Lagrange multiplier of this constraint. We obtain the opposite result if $\alpha$ is set above $\alpha^{*}$. Finally, if $\alpha$ is set at too extreme a level (too low or too high), it may become impossible for the USP to satisfy the constraint in that no set of prices can be found that will allow the USP to breakeven. To consider this issue further we use numerical simulations.

\subsection{Introducing bypass}

We now consider the possibility that entrants are able to bypass the USP delivery network. Bypass then will occur in area $i$ if $a_{i}>d_{i}^{E}$. We assume (as will be the case in the numerical simulations) that bypass occurs in the urban area only, i.e., that $a_{U}>d_{U}^{E}, a_{R}<d_{R}^{E}$. We further assume that the USP is not allowed by the regulator to undercut the entrants' delivery cost in order to prevent bypass from occurring. On the other hand, the USP anticipates that bypass will occur if the optimal urban access charge it chooses in the previous two sub-sections is larger than the entrants' delivery cost. In that case, the USP has to integrate in its optimisation that bypass will prevail in the urban area - i.e., first order conditions in the previous two sections have to be modified to take into account that no profit will be made by the USP through selling access to its delivery network in the urban area. This is straightforward (and indeed simplifies the analysis compared to the section above). First note that the analytical formulations for the optimal singlepiece mail price, rural bulk mail price and rural access charge are not affected by the availability of urban bypass (although the equilibrium values of these prices are affected because of changes in the value of the Lagrange multipliers at equilibrium). So for instance, the optimality conditions for $q, p_{R}^{I}$ and $a_{R}$ 
are still given by (3), (4) and (5) above in the case of the Ramsey program accompanied by a minimum margin requirement. For the urban bulk mail price, equation (4) then simplifies to

$$
\lambda y_{i}^{I}+(1+\lambda)\left(p_{i}^{I}-c^{I}-d_{i}^{I}\right) \frac{\partial y_{i}^{I}}{\partial p_{i}^{I}}=0
$$

which gives the classical Ramsey price formulation.

\section{Calibration}

We now go beyond the consideration of first order conditions, in order to compare price, volume and welfare levels attained under the various price control procedures. Use of numerical simulations through a calibrated version of the model is especially important in assessing the impact of allowing for (urban) bypass, since first order conditions are not well suited to the case of a binary decision such as bypass.

Our calibration assumptions are based on De Donder et al. (2006a), modified to take into account the fact that we have modelled two delivery areas here. The assumptions are not estimates from a particular postal operator, but our assessment is that they reflect well the general nature of postal markets and cost structures given published empirical studies. ${ }^{5}$ We start from the hypothetical situation where the USP does not face any entry. We assume that the USP posts a price of 0.50 euro for the single piece product and a price of 0.40 euro for its bulk mail product. Total quantities sold at those prices are, respectively, 2 billion and 8 billion items. We assume that $80 \%$ of all mail flows are urban while $20 \%$ are rural, and that the direct price elasticities are -0.2 for single-piece mail and -0.4 for bulk mail (same elasticity in urban and rural markets). Finally, we calibrate linear demands based on these quantities, prices and elasticities.

We need further information to calibrate the demand functions for bulk mail products when the market is opened to competition. We use two types of information: the extent of entry for different price configurations and the substitutability between the two bulk mail products for consumers. With regard to the extent of entry, we assume that entrants would capture $10 \%$ of the total market for bulk mail if both bulk mail products had the same price, and $50 \%$ of the market if entrants were to offer a $20 \%$ price discount over the USP. On substitution between those products, we assume that the

\footnotetext{
${ }^{5}$ With regard to demand, see for example Florens et al (2002), Nankervis et al (2002) and Tolley (2000); while on costs see for example Cazals et al (2005).
} 
displacement ratio (given by $\left.-\left(\partial y_{i}^{I} / \partial p_{i}^{E}\right) /\left(\partial y_{i}^{E} / \partial p_{i}^{E}\right)\right)$ is set at 0.75 in both areas, which means that three quarters of the quantities sold by entrants are effectively displaced from the USP, while one quarter represents additional volumes sold in the sector.

Table 1: Cost calibration

\begin{tabular}{|c|c|c|c|c|c|}
\hline & & \multicolumn{2}{|l|}{ USP } & \multicolumn{2}{|l|}{ entrants } \\
\hline & & urban & rural & \multirow[t]{3}{*}{ urban } & \multirow[t]{3}{*}{ rural } \\
\hline \multirow[t]{2}{*}{ Single-piece } & upstream & \multicolumn{2}{|c|}{$c_{x}=0.18$} & & \\
\hline & delivery & & & \\
\hline \multirow[t]{2}{*}{ Bulk-mail } & upstream & \multicolumn{2}{|c|}{$c^{I}=0.12$} & \multicolumn{2}{|c|}{$c^{E}=0.15$} \\
\hline & delivery & $d_{U}^{I}=0.11$ & $d_{R}^{I}=0.16$ & $d_{U}^{E}=0.15$ & $d_{R}^{E}=0.36$ \\
\hline Fixed cost & & \multicolumn{2}{|c|}{$F=1680$} & \multicolumn{2}{|c|}{0} \\
\hline
\end{tabular}

The USP unit upstream cost is equal to 0.18 euro for single-piece mail and 0.12 euro for bulk mail. The USP urban delivery cost (for both kinds of mail) is 0.11 euro in the urban area and 0.16 euro in the rural area. The value of the fixed cost $F$ equals 1680 million euros so that the USP breaks even in the hypothetical monopoly situation (including a normal rate of profit, $F$ equals $40 \%$ of revenue of $4.2 \mathrm{bn}$ ).

The entrants's collection cost $c^{E}$ is set at 0.15 euro, its delivery cost at 0.15 euro in the urban area and 0.36 euro in the rural area. The entrants do not face any fixed cost but we assume instead that entrants have higher variable collection and delivery costs than the USP.

\section{Results}

\subsection{Monopoly}

Table 2 contains the results of the simulations carried out with the model calibrated in the previous section. It reports prices (in euros), quantities (in billion items), contributions to the USP profit and net user surpluses (both in billions of euros) for various scenarios. The first scenario studied, which we will use as a benchmark, corresponds to the second-best (Ramsey) optimal prices in the monopoly situation. It is reported under the heading Ramsey in Table 2. Observe that these optimal prices differ from the prices we have used to calibrate the model: the single-piece price $q$ is higher ( 0.609 euro instead of 0.5 euro) while the bulk mail prices are differentiated according to the delivery area. The contributions to the USP profit add up to 1.680 
billion euros which is the value of the USP fixed cost. The selling of singlepiece letters allows $35.1 \%$ of this fixed cost to be covered with the rest being financed by the bulk mail products. The total welfare attained in this setting is 6.510 billion euros and is constituted exclusively of user surpluses.

\subsection{Competitive entry through access only}

We now turn to the opening of the market to competition. The next three columns in Table 2 assume that bypass is unavailable to the entrants. We first look at the second-best optimal prices under competition and compare them with the optimal prices under monopoly. We obtain given our calibration that the E2E USP prices are barely affected by the opening to competition and decrease very slightly. The single-piece volumes, contributions to the covering of the fixed costs and the user surplus they generate are then also unaffected. The USP bulk mail volumes decrease in both delivery areas, but this is more than compensated by the volumes sold by the entrants. The contribution to the USP profit of the bulk mail products decreases and the selling of access compensates $6.3 \%$ of the fixed costs. Consumers benefit from the availability of the entrants' bulk mail products and the economies of scale from higher volumes being delivered through the USP's network so that total welfare increases to 6.526 billion euros.

The next column in Table 2 considers the case where a constraint is imposed on the minimum price difference (or "margin") between the bulk mail price and the access charge in any given area. Note that, for the secondbest optimal prices, this margin is equal to 0.149 euro in the urban market and 0.255 euro in the rural market. In the column headed "Min Margin", we impose the constraint that the margin should be equal to at least 0.17 euro $^{6}$, so that this constraint binds at the optimum for the urban market but not for the rural market. Comparing these results with the optimal prices without this constraint, we obtain that the USP decreases its urban access charge and increases its urban bulk mail price to satisfy the margin constraint. Other prices are also affected: the single-piece price and the rural access charge decrease while the rural bulk mail price increases. The entrants' prices decrease since both access charges decrease. With regard to the volumes, the number of single-piece letters increases, which in turn increases the net user surplus. The entrants' bulk mail volumes increase at the expense of the USP's but overall volumes are higher than both the GPC

\footnotetext{
${ }^{6}$ We wish to consider the effect of the minimum price difference being greater than that consistent with the set of optimal prices (0.149 euro). In this regard the specific value chosen of 0.17 euro meets this requirement although a higher or lower value (above 0.149 euro) would have served equally to consider the impact of this constraint binding.
} 
cases so that the constraint on the margin induces both additional entry and higher market volumes. The share of fixed cost covered by the selling of single-piece mail decreases to $32 \%$, while the share covered by the selling of access increases to $10.4 \%$. The loss of user surplus in the bulk mail market is larger than the gain in surplus in the single-piece market, so that total welfare decreases compared to GPC to 6.515 billion euros.

We now turn to the price control mechanism where the regulator imposes two separate price caps on the USP, with one cap on single-piece mail and another cap on a second basket, composed of bulk mail and of access products. This case is identified by the heading " 2 basket" in Table 2 . We assume that the regulator imposes the same cap on single-piece mail as the price used in the hypothetical monopoly situation used to calibrate the model, i.e., that $q=0.5$ euro. This means that the profit made by selling single-piece letters covers $23.8 \%$ of the USP fixed cost. This proportion is lower than the one obtained in the Ramsey case, so using the notation introduced in section 3.2., we have that $\alpha<\alpha^{*}$. We then assume that the second price cap is set optimally by the regulator, conditional on the constraint that this basket should fund the remaining $76.2 \%$ of the fixed cost. Compared with the Ramsey case, all prices in the second basket (bulk mail and access) are higher, volumes are lower including those for the market overall and user surpluses from bulk mail are lower. The total welfare level attained decreases compared to the second-best level, and it happens to be close to the level obtained under the "Min Margin" scenario.

Observe that the gap between the single-piece price and the rural USP bulk mail price is very low in the this scenario (0.047 euro). This means that, if the preparation cost incurred by bulk mail senders is larger than 0.047 euro, non residential senders would pay less to use single-piece mail than bulk mail in the rural area. Obviously, if this constraint is binding at the optimum, it will lead to lower welfare levels than those reported in Table 2 .

\subsection{Competitive entry through access and bypass}

We now look at the impact of allowing for bypass on the equilibrium prices, volumes and welfare. Observe that the optimal access charge with a GPC is larger than the entrants's delivery cost on the urban area (0.21 euro compared to 0.15 euro) while it is lower in the rural area (0.269 euro compared to 0.36 euro). This would result in urban bypass by the entrants, a situation we model in the last column of Table 2. More precisely, we study the second-best optimal prices when the USP does not provide access to its urban delivery network. Comparing this case with the situation without urban bypass, we 
obtain that the USP reacts to the loss of urban access volumes by increasing its single-piece price by more than 0.24 euro. As a consequence, the share of fixed costs covered by the single piece product increases from $35.1 \%$ to $56.5 \%$. Both the rural access charge and the price paid for the USP's rural bulk mail also increase with bypass. The bulk mail products offered by the two competitors are strategic complements, so the urban USP bulk mail price decreases when the entrants's bulk mail price decreases due to bypass. With regard to welfare, user surplus decreases for all products except urban bulk mail. Total welfare decreases with bypass and is even lower than the welfare level attained in the monopoly situation under this calibration although volumes are higher than in the other cases so that the decline in welfare is relatively modest. This result confirms the similar results we have obtained in De Donder et al. (2006a) and De Donder (2006).

By extension, from these papers and from the results for no bypass, the additional constraints in the "min margin" and "2 basket" cases would reduce total welfare further in the case of bypass compared with the no bypass and monopoly cases (see De Donder et al. (2006b)).

\subsection{Robustness}

We test the robustness of our results to two assumptions: the degree of differentiation between bulk mail products offered by both competitors (measured by the displacement ratio) and entrants' efficiency.

In the case of a higher differentiation, where the displacement ratio is lowered from 0.75 to 0.6 and reported in Table 3, the ranking of the different cases is not affected by this change: the highest level of welfare is attained under competition with Ramsey prices and no bypass possibility. Adding constraints to the Ramsey problem, such as a minimum margin between prices or separating goods in two baskets decreases the welfare level, which nevertheless remains larger than the highest welfare level attainable in the monopoly situation. On the other hand, allowing for bypass in the Ramsey case results in urban bypass and in a total welfare level lower than the monopoly situation. The price of single piece mail again rises very substantially in this case. Finally, modifying the degree of product differentiation affects which (if any) minimum margin constraint is binding, and also the size of the welfare cost of adding such a constraint, or of splitting the mail products in two baskets.

As a second sensitivity, we assume that the entrants are more efficient than the USP both for collection (0.09 euro cost compared to 0.12 euro for the USP, and to 0.15 euro in the benchmark calibration) and for urban delivery (0.07 euro cost compared to 0.11 euro for the USP, and to 0.15 euro in the 
benchmark calibration). As for rural delivery, we maintain the assumption that it would be extremely costly for the entrants to build a delivery network there. Results for these cost calibrations (together with the original value for the displacement ratio between bulk mail products of 0.75 ) are reported in Table 4.

We first obtain that welfare increases in all cases when the entrants are more efficient. If bypass is not available, the USP reacts to more efficient entrants by increasing its access charges and decreasing its bulk mail prices. The total quantity sold by the entrants increases significantly, and the business of selling access takes a lot more importance for the USP, because of both the higher volumes and the higher margins made on this business. The welfare cost of imposing minimum margin constraints or two baskets are quite small (in terms of the welfare gain of moving from the optimal monopoly situation to the optimal competitive situation): this makes sense, since the opening to competition increases total welfare more when entrants' costs are low. The picture is very different once bypass is available: total welfare increases, but all the gains from having lower entrants' costs are captured by consumers of urban bulk mail, while other consumers lose surplus because of the very large increase in the USP single-piece price.

\section{Introducing a universal service fund}

Up to now, we have assumed that the USP's fixed cost has to be financed by the USP selling (single-piece and bulk ) mail products as well as access to the entrants. One problem we have identified with this method is that the markup over the marginal access cost may induce the entrants to (inefficiently) bypass the USP delivery network, especially in the urban area. Another way to finance (at least in part) the USP fixed cost is to impose a tax on the entrants' output ${ }^{7}$, whose proceeds would be directed into a universal service fund that would reimburse the USP for (part of) its fixed cost. The main advantage of this output tax is that, unlike a mark-up over the marginal access cost, it does not induce inefficient bypass of the USP network, since the output tax has to be paid by the entrants whatever their delivery method (see Armstrong 2006).

More precisely, we assume that a specific tax of $\tau$ euro is imposed on the entrants' output, whose proceeds go into the universal service fund. The

\footnotetext{
${ }^{7}$ Alternatively, we could assume that the USP also has to pay the output tax. This would not change the results we obtain below, since the USP price-cost margin is already an implicit output tax.
} 
value of this tax is set exogenously by the regulator. ${ }^{8}$ Formally, to the USP profit formula (equation (14) in the appendix), we now add the tax proceeds -i.e., $\tau\left(y_{U}^{E}\left(p_{U}^{I}, p_{U}^{E}\right)+y_{R}^{E}\left(p_{R}^{I}, p_{R}^{E}\right)\right)$. We keep the assumption of a competitive fringe behaviour of the entrants, so that entrants break even with $p_{i}^{E}=$ $c^{E}+\tau+\min \left(a_{i}, d_{i}^{E}\right), i=U, R$. It is clear that the value of the tax does not impact the bypass decision of the entrants.

We first look at the impact of imposing an exogenous tax $\tau$ in the cases where bypass is not available to the entrants. In these cases, the $\operatorname{tax} \tau$ and the access charges $a_{U}$ and $a_{R}$ are perfectly substitutable: it is the sum of $\tau$ and $a_{U}$ and of $\tau$ and $a_{R}$ that matters both to the entrants's price and to the USP profit, and any increase in the exogenous $\tau$ results in a decrease of the same amount of both access charges. Intuitively, taxing output and posting a mark-up over the marginal access costs produce identical results when the postal production technology is such that one unit of input (use of USP delivery network) is always needed to produce one unit of output (bulk mail).

Consider next the case where bypass is allowed. Recall that, in our benchmark simulations reported in Table 2, urban bypass occurs in the Ramsey scenario because the optimal access charge in that case $(0.21$ euro - second column in Table 2$)$ is larger than the entrants' delivery cost ( 0.15 euro). This corresponds to the case where $\tau=0$. Increasing $\tau$ from 0 results in a decrease by the same amount of both $a_{U}$ and $a_{R}$. Because of the substitutability between $\tau$ and the access charges, the optimum urban access charge (when the USP does not take bypass possibilities into account) stays larger than 0.15 euro as long as $\tau$ is smaller than 0.06 euro. On the other hand, for $\tau$ larger than 0.06 euro, the optimal access charge becomes smaller than the entrants's delivery cost, and the entrants choose access rather than bypass.

Table 5 illustrates numerically these results for the Ramsey case when bypass is available to the entrants. The first column corresponds to $\tau=0-$ i.e., the case with urban bypass reported in the last column of Table 2 . The next three columns correspond to positive values of $\tau$ (0.01 euro, 0.03 euro and 0.05 euro) smaller than 0.06 euro - i.e., to cases where urban bypass occurs because 0.21 euro $-\tau>0.15$ euro. The last column corresponds to the case where $\tau$ is exogenously set at a value larger than 0.06 euro - i.e., when the value of $\tau$ is large enough to allow the USP to decrease its urban access charge below the entrants' delivery cost.

We now look at the impact of increasing the exogenous $\operatorname{tax} \tau$ on equilibrium prices, volumes, contributions to USP profit and user surpluses in the

\footnotetext{
${ }^{8}$ Our focus below is on how the value of the output tax rate affects the market equilibrium, rather than in finding its second-best optimal level.
} 
Ramsey case. Increasing $\tau$ allows the USP to post a lower single-piece mail price, resulting in higher volumes and higher user surpluses. Increasing $\tau$ generates an increase in the USP bulk mail price and a decrease in the USP rural bulk mail price. The entrants' prices move in the same direction as the USP bulk mail prices. These price changes produce an increase in the USP's bulk mail volumes, a decrease in the entrants's urban bulk mail volumes, and have a non monotone impact on the USP rural bulk mail volume. The impact of a larger $\tau$ on total postal volumes are also non monotone, with first a decrease and then an increase.

The contribution to the USP profit of single-piece mail (both urban and rural) decreases with $\tau$. The share of urban bulk mail increases while that of rural bulk mail decreases. Interestingly, the share of tax proceeds is non monotone: it is first increasing, then decreasing in $\tau$. Observe that this share stays quite low, of the order of $1 \%$ of total fixed costs, as long as bypass occurs. Finally, the surplus of all consumers increases, except for the urban bulk mail buyers. Total welfare increases with the tax, but stays below the monopoly level ( 6.510 bn euros) as long as the tax is below that resulting in bypass.

The main results we obtain with entrants' output taxation are as follows. If bypass does not occur, the output tax and the access charge levels are perfect substitutes, and the equilibrium is not affected by the precise value of the tax. If bypass occurs, the value of the tax has an impact on the equilibrium: a higher tax leads to a lower single-piece mail price and higher urban bulk mail prices, so that total welfare increases even though urban bulk mail consumers' surplus decreases.

\section{Conclusion}

In setting price controls, regulators in the postal sector may consider additional objectives to the goals of ensuring the continuing provision of universal service and maximising allocative efficiency and, hence, introduce procedures to meet these additional objectives. In this paper, we have explored aspects of these issues by considering the impacts and effects of regulators in the postal sector adopting price control procedures that seek to achieve objectives other than the maximisation of allocative efficiency and economic welfare. Clearly these procedures result in lower levels of welfare than those from the benchmark of GPC.

Our initial results from the numerical calibration of our model indicate that in the case where entry is confined only to access, a range of procedures appear capable of meeting objectives for universal service, equity and 
competitive entry, prospectively, with quite small adverse impacts on economic welfare. If these non-efficiency objectives are valued highly then it appears that the welfare costs of meeting them may be worth incurring at least at the calibration values initially adopted in our model. However, if bypass is available these trade offs become more costly. Under GPC, welfare is lower and the single piece price significantly higher than when only access is available to potential entrants. By extension from the no bypass case, the welfare costs and potential for non-achievement of at least some objectives increase with the extent of entry through bypass. We consider also the effect of introducing a universal service fund.

Our analysis has considered these price control procedures individually. However, where a regulator is seeking to achieve a number of objectives simultaneously this may lead to the combined application of some of these procedures or their application with other similar rules and constraints. This is likely to lead to further divergence from the GPC benchmark. Under these circumstances also there is an increase in the likelihood that one or more objectives may not be met or only met by violating the breakeven constraint. Such possibilities and trade-offs can be explored further through our model by examining a range of parameter values and combinations of non-optimal procedures.

\section{References}

[1] Armstrong, M. (2002), "The theory of access pricing and interconnection", in Handbook of Telecommunication, vol 1., edited by M. Cave et al., 295-386.

[2] Armstrong, M. (2006), "Access Pricing, Bypass and Universal Service in Post", mimeo University College London.

[3] Billette de Villemeur, E, H. Cremer, B. Roy. and J. Toledano (2003), "Optimal pricing and global price-cap in the postal sector", Journal of Regulatory Economics, 24, 49-62.

[4] Cazals, C., J-P Florens and S. Soteri (2005), "Delivery Costs for Postal Services in the UK: Some Results on Scale economies with Panel Data", in Regulatory and Economic Challenges in the Postal and Delivery Sector, edited by M.A. Crew and P.R. Kleindorfer, Boston, MA: Kluwer Academic Publishers, 203-212.

[5] Crew M. and P. Kleindorfer (1995), "Pricing in Postal Service under Competitive Entry", in Commercialization of Postal and Delivery Ser- 
vices, edited by M. A. Crew and P. R. Kleindorfer, Boston : Kluwer Academic Publishers, 117-136.

[6] De Donder, Ph. (2006), "Access Pricing in the Postal Sector: Theory and Simulations", Review of Industrial Organization, 28-3: 307-326.

[7] De Donder, Ph., H. Cremer, P. Dudley and F. Rodriguez (2006a), "Pricing and Welfare Implications of Alternative Approaches to Setting Price Controls in the Postal Sector" in Progress toward Liberalization of the Postal and Delivery Sector, edited by M.A. Crew and P.R. Kleindorfer, New York: Springer, 227-248.

[8] De Donder Ph., H. Cremer, P. Dudley and F. Rodriguez (2006b). "A Welfare Analysis of Price Controls with End-to-end Mail and Access Services", in Liberalization of the Postal and Delivery Sector, edited by M. A. Crew and P. R. Kleindorfer, Cheltenham: Edward Elgar, 53-72.

[9] Florens, J-P, Marcy S. and J. Toledano (2002), "Mail Demand in the Long and the Short Term", in Postal and Delivery Services: Pricing, Productivity, Regulation and Strategy, edited by M.A. Crew and P.R. Kleindorfer, Boston, MA: Kluwer Academic Publishers, 171-190.

[10] Laffont, J.J. and J. Tirole (1996), "Creating competition through interconnection: Theory and practice", Journal of Regulatory Economics, 10, $227-256$.

[11] Nankervis, J., S. Richard, S. Soteri. and F. Rodriguez (2002), "Disaggregated Letter Traffic Demand in the UK", in Postal and Delivery Services: Pricing, Productivity, Regulation and Strategy, edited by M.A. Crew and P.R. Kleindorfer, Boston, MA: Kluwer Academic Publishers, 203-220.

[12] Panzar, J. (2004), "Combining liberalization and unbundling policies in postal markets", mimeo Northwestern University and University of Auckland.

[13] Postal Services Commission (2006), Amended Licence Granted to Royal Mail Group plc, 25 may 2006. Condition (21).

[14] Tolley, G. (2000), Direct Testimony (sponsored by the United States Postal Service) as USPS-T-6 in Docket No R2000-01 before the Postal rate Commission. 
Table 2: Simulations results ${ }^{9}$

\begin{tabular}{|c|c|c|c|c|c|c|}
\hline & & \multirow[t]{2}{*}{ Monopoly } & \multicolumn{4}{|c|}{ Competition } \\
\hline & & & \multicolumn{3}{|c|}{ No Bypass } & \multirow{2}{*}{$\begin{array}{l}\text { Bypass } \\
\text { Ramsey }\end{array}$} \\
\hline & & Ramsey & Ramsey & Min Margin & 2 basket & \\
\hline \multicolumn{7}{|l|}{ Prices: } \\
\hline -single-piece & $q$ & 0.609 & 0.608 & 0.577 & 0.500 & 0.853 \\
\hline \multirow[t]{2}{*}{-USP bulk } & $\mathbf{p}_{U}^{I}$ & 0.360 & 0.359 & 0.372 & 0.386 & 0.287 \\
\hline & $\mathbf{p}_{R}^{I}$ & 0.424 & 0.424 & 0.432 & 0.453 & 0.538 \\
\hline \multirow[t]{2}{*}{-access } & $\mathbf{a}_{U}$ & - & 0.210 & 0.202 & 0.231 & - \\
\hline & $\mathbf{a}_{R}$ & - & 0.269 & 0.262 & 0.292 & 0.357 \\
\hline \multirow[t]{2}{*}{-entrants } & $\mathbf{p}_{U}^{E}$ & - & 0.360 & 0.352 & 0.381 & 0.300 \\
\hline & $\mathbf{p}_{R}^{E}$ & - & 0.419 & 0.412 & 0.442 & 0.507 \\
\hline \multicolumn{7}{|l|}{ Quantities: } \\
\hline \multirow[t]{3}{*}{-single-piece } & $\mathbf{x}_{U}$ & 1.531 & 1.531 & 1.551 & 1.600 & 1.374 \\
\hline & $\mathbf{x}_{R}$ & 0.383 & 0.383 & 0.388 & 0.400 & 0.344 \\
\hline & Total & 1.913 & 1.914 & 1.939 & 2.000 & 1.718 \\
\hline \multirow[t]{3}{*}{-USP bulk } & $\mathbf{y}_{U}^{I}$ & 6.599 & 5.909 & 5.319 & 5.753 & 6.221 \\
\hline & $\mathbf{y}_{R}^{I}$ & 1.623 & 1.526 & 1.411 & 1.486 & 1.370 \\
\hline & Total & 8.222 & 7.435 & 6.730 & 7.239 & 7.591 \\
\hline \multicolumn{2}{|c|}{ Total USP volumes } & 10.135 & 9.349 & 8.669 & 9.239 & 9.308 \\
\hline \multirow[t]{3}{*}{-Entrant's bulk } & $\mathbf{y}_{U}^{E}$ & - & 0.922 & 1.601 & 0.898 & 1.142 \\
\hline & $\mathbf{y}_{R}^{E}$ & - & 0.130 & 0.266 & 0.126 & 0.116 \\
\hline & Total & - & 1.052 & 1.867 & 1.024 & 1.258 \\
\hline \multicolumn{2}{|c|}{ Total market volumes } & 10.135 & 10.401 & 10.536 & 10.263 & 10.567 \\
\hline
\end{tabular}

\footnotetext{
${ }^{9}$ Prices are in euros and volumes in billion items.
} 
Table 2 (continued): Simulations results ${ }^{10}$

\begin{tabular}{|c|c|c|c|c|c|c|}
\hline & & \multirow{3}{*}{$\begin{array}{l}\text { Monopoly } \\
\text { Ramsey } \\
\end{array}$} & \multicolumn{4}{|c|}{ Competition } \\
\hline & & & \multicolumn{3}{|c|}{ No Bypass } & Bypass \\
\hline & & & Ramsey & Min Margin & 2 basket & Ramsey \\
\hline \multicolumn{7}{|c|}{ Contributions to Profit } \\
\hline \multirow[t]{2}{*}{-single-piece } & urban & 0.488 & 0.487 & 0.445 & 0.336 & 0.774 \\
\hline & rural & 0.103 & 0.103 & 0.092 & 0.064 & 0.176 \\
\hline \multirow[t]{2}{*}{-USP's bulk } & urban & 0.856 & 0.765 & 0.754 & 0.897 & 0.354 \\
\hline & rural & 0.234 & 0.219 & 0.215 & 0.257 & 0.354 \\
\hline \multirow[t]{2}{*}{-Access } & urban & - & 0.092 & 0.147 & 0.108 & - \\
\hline & rural & - & 0.014 & 0.027 & 0.017 & 0.023 \\
\hline \multicolumn{2}{|c|}{ Share of single-piece } & 0.351 & 0.351 & 0.319 & 0.238 & 0.565 \\
\hline \multicolumn{2}{|c|}{ Share of Access } & - & 0.063 & 0.104 & 0.074 & 0.014 \\
\hline \multicolumn{7}{|c|}{ Net User Surpluses } \\
\hline \multirow[t]{2}{*}{-single-piece } & urban & 1.830 & 1.831 & 1.879 & 2.000 & 1.475 \\
\hline & rural & 0.458 & 0.458 & 0.470 & 0.500 & 0.369 \\
\hline \multirow[t]{2}{*}{-bulk } & urban & 3.317 & 3.330 & 3.271 & 3.156 & 3.832 \\
\hline & rural & 0.906 & 0.907 & 0.896 & 0.860 & 0.731 \\
\hline Sum & & 6.510 & 6.526 & 6.515 & 6.516 & 6.407 \\
\hline
\end{tabular}

\footnotetext{
${ }^{10}$ Profit and surpluses are in billion euros.
} 
Table 3: Simulations results ${ }^{11}$ with $\sigma=0.6$

\begin{tabular}{|c|c|c|c|c|c|c|}
\hline & & \multirow{3}{*}{$\begin{array}{l}\text { Monopoly } \\
\text { Ramsey } \\
\end{array}$} & \multicolumn{4}{|c|}{ Competition } \\
\hline & & & \multicolumn{3}{|c|}{ No Bypass } & \multirow{2}{*}{$\begin{array}{l}\text { Bypass } \\
\text { Ramsey }\end{array}$} \\
\hline & & & Ramsey & Min Margin & 2 basket & \\
\hline \multicolumn{7}{|l|}{ Prices: } \\
\hline -single-piece & q & 0.609 & 0.606 & 0.599 & 0.500 & 0.839 \\
\hline \multirow[t]{2}{*}{-USP bulk } & $\mathbf{p}_{U}^{I}$ & 0.360 & 0.359 & 0.362 & 0.385 & 0.296 \\
\hline & $\mathbf{p}_{R}^{I}$ & 0.424 & 0.423 & 0.420 & 0.452 & 0.532 \\
\hline \multirow[t]{2}{*}{-access } & $\mathbf{a}_{U}$ & - & 0.193 & 0.192 & 0.209 & - \\
\hline & $\mathbf{a}_{R}$ & - & 0.249 & 0.247 & 0.267 & 0.317 \\
\hline \multirow[t]{2}{*}{-entrants } & $\mathbf{p}_{U}^{E}$ & - & 0.343 & 0.342 & 0.359 & 0.300 \\
\hline & $\mathbf{p}_{R}^{E}$ & - & 0.399 & 0.397 & 0.417 & 0.467 \\
\hline \multicolumn{7}{|l|}{ Quantities: } \\
\hline \multirow[t]{3}{*}{-single-piece } & $\mathbf{x}_{U}$ & 1.531 & 1.532 & 1.537 & 1.600 & 1.383 \\
\hline & $\mathbf{x}_{R}$ & 0.383 & 0.383 & 0.384 & 0.400 & 0.346 \\
\hline & Total & 1.913 & 1.915 & 1.921 & 2.000 & 1.729 \\
\hline \multirow[t]{3}{*}{-USP bulk } & $\mathbf{y}_{U}^{I}$ & 6.599 & 5.478 & 5.385 & 5.337 & 5.766 \\
\hline & $\mathbf{y}_{R}^{I}$ & 1.623 & 1.449 & 1.453 & 1.412 & 1.308 \\
\hline & Total & 8.222 & 6.927 & 6.838 & 6.749 & 7.074 \\
\hline \multicolumn{2}{|c|}{ Total USP volumes } & 10.135 & 8.842 & 8.759 & 8.749 & 8.803 \\
\hline \multirow[t]{3}{*}{-Entrant's bulk } & $\mathbf{y}_{U}^{E}$ & - & 1.879 & 1.994 & 1.831 & 2.090 \\
\hline & $\mathbf{y}_{R}^{E}$ & - & 0.293 & 0.294 & 0.286 & 0.265 \\
\hline & Total & - & 2.172 & 2.288 & 2.117 & 2.355 \\
\hline \multicolumn{2}{|c|}{ Total market volumes } & 10.135 & 11.015 & 11.047 & 10.865 & 11.158 \\
\hline
\end{tabular}

\footnotetext{
${ }^{11}$ Prices are in euros and volumes in billion items.
} 
Table 3 (continued): Simulations results ${ }^{12}$ with $\sigma=0.6$

\begin{tabular}{|c|c|c|c|c|c|c|}
\hline & & \multirow{3}{*}{$\begin{array}{l}\text { Monopoly } \\
\text { Ramsey } \\
\end{array}$} & \multicolumn{4}{|c|}{ Competition } \\
\hline & & & \multicolumn{3}{|c|}{$\begin{array}{l}\text { Competition } \\
\text { No Bypass }\end{array}$} & \multirow{2}{*}{$\begin{array}{l}\text { Bypass } \\
\text { Ramsey }\end{array}$} \\
\hline & & & Ramsey & Min Margin & 2 basket & \\
\hline \multicolumn{7}{|c|}{ Contributions to Profit } \\
\hline \multirow[t]{2}{*}{-single-piece } & urban & 0.488 & 0.484 & 0.475 & 0.336 & 0.759 \\
\hline & rural & 0.103 & 0.102 & 0.100 & 0.064 & 0.173 \\
\hline \multirow[t]{2}{*}{-USP's bulk } & urban & 0.856 & 0.705 & 0.713 & 0.825 & 0.378 \\
\hline & rural & 0.234 & 0.207 & 0.203 & 0.242 & 0.329 \\
\hline \multirow[t]{2}{*}{-Access } & urban & - & 0.156 & 0.164 & 0.182 & - \\
\hline & rural & - & 0.026 & 0.026 & 0.031 & 0.041 \\
\hline \multicolumn{2}{|c|}{ Share of single-piece } & 0.351 & 0.349 & 0.342 & 0.238 & 0.555 \\
\hline \multicolumn{2}{|c|}{ Share of Access } & - & 0.108 & 0.113 & 0.127 & 0.025 \\
\hline \multicolumn{7}{|c|}{ Net User Surpluses } \\
\hline \multirow[t]{2}{*}{-single-piece } & urban & 1.830 & 1.834 & 1.845 & 2.000 & 1.494 \\
\hline & rural & 0.458 & 0.458 & 0.461 & 0.500 & 0.374 \\
\hline \multirow[t]{2}{*}{-bulk } & urban & 3.317 & 3.365 & 3.346 & 3.194 & 3.805 \\
\hline & rural & 0.906 & 0.911 & 0.917 & 0.865 & 0.743 \\
\hline Sum & & 6.510 & 6.569 & 6.568 & 6.559 & 6.416 \\
\hline
\end{tabular}

\footnotetext{
${ }^{12}$ Profit and surpluses are in billion euros.
} 
Table 4: Simulations results ${ }^{13}$ with $c^{E}=0.09, d_{U}^{E}=0.07$

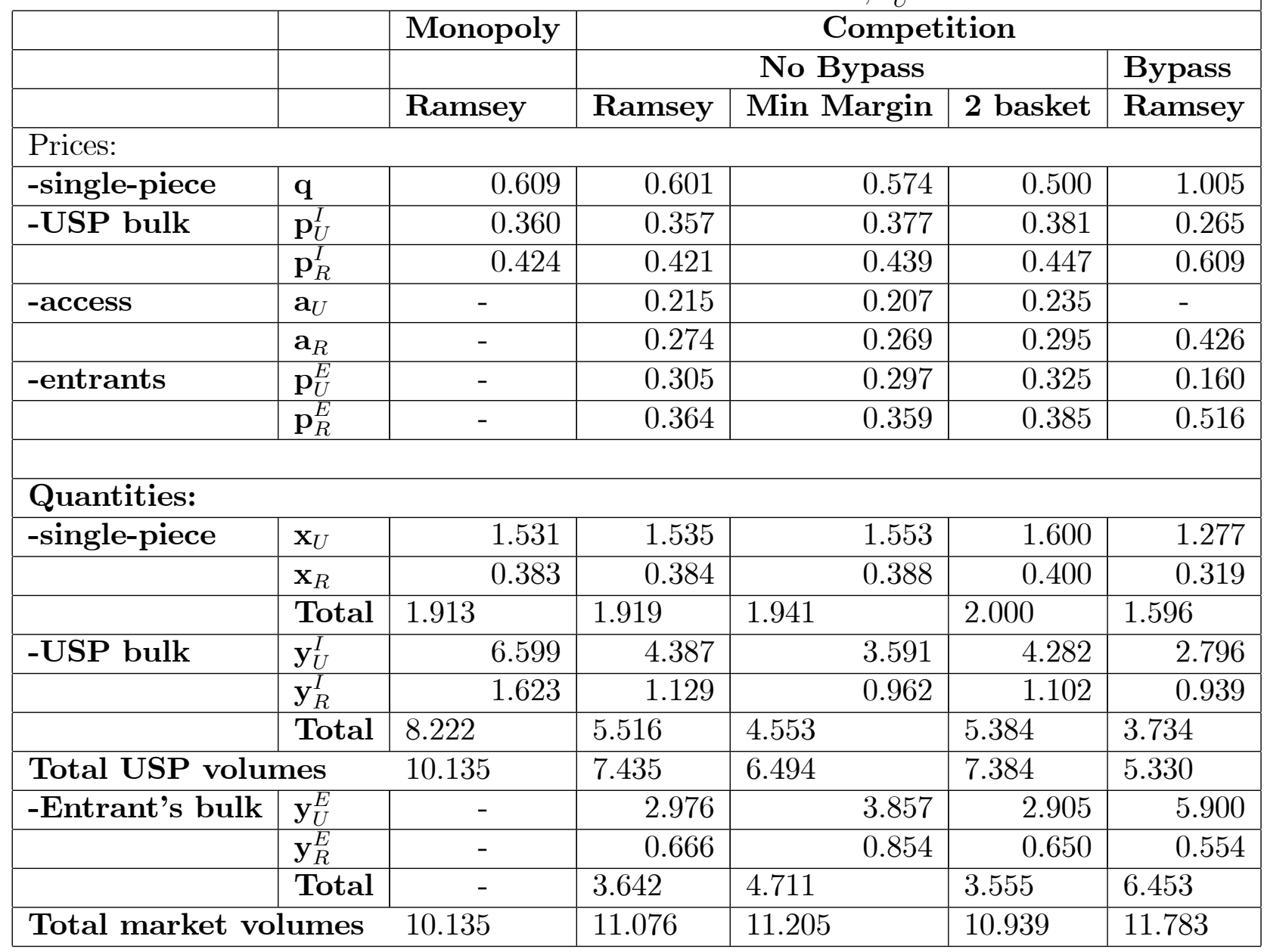

\footnotetext{
${ }^{13}$ Prices are in euros and volumes in billion items.
} 
Table 4 (continued): Simulations results ${ }^{14}$ with $\sigma=0.6$

\begin{tabular}{|c|c|c|c|c|c|c|}
\hline & & \multirow{3}{*}{$\begin{array}{l}\text { Monopoly } \\
\text { Ramsey } \\
\end{array}$} & \multicolumn{4}{|c|}{ Competition } \\
\hline & & & \multicolumn{3}{|c|}{ No Bypass } & \multirow{2}{*}{$\begin{array}{l}\text { Bypass } \\
\text { Ramsey }\end{array}$} \\
\hline & & & Ramsey & Min Margin & 2 basket & \\
\hline \multicolumn{7}{|c|}{ Contributions to Profit } \\
\hline \multirow[t]{2}{*}{-single-piece } & urban & 0.488 & 0.478 & 0.440 & 0.336 & 0.913 \\
\hline & rural & 0.103 & 0.100 & 0.091 & 0.064 & 0.212 \\
\hline \multirow[t]{2}{*}{-USP's bulk } & urban & 0.856 & 0.556 & 0.529 & 0.646 & 0.098 \\
\hline & rural & 0.234 & 0.159 & 0.153 & 0.184 & 0.309 \\
\hline \multirow[t]{2}{*}{-Access } & urban & - & 0.312 & 0.375 & 0.362 & - \\
\hline & rural & - & 0.076 & 0.093 & 0.088 & 0.148 \\
\hline \multicolumn{2}{|c|}{ Share of single-piece } & 0.351 & 0.344 & 0.316 & 0.238 & 0.670 \\
\hline \multicolumn{2}{|c|}{ Share of Access } & - & 0.231 & 0.278 & 0.268 & 0.088 \\
\hline \multicolumn{7}{|c|}{ Net User Surpluses } \\
\hline \multirow[t]{2}{*}{-single-piece } & urban & 1.830 & 1.841 & 1.884 & 2.000 & 1.273 \\
\hline & rural & 0.458 & 0.460 & 0.471 & 0.500 & 0.318 \\
\hline \multirow[t]{2}{*}{-bulk } & urban & 3.317 & 3.452 & 3.396 & 3.289 & 4.423 \\
\hline & rural & 0.906 & 0.933 & 0.919 & 0.889 & 0.645 \\
\hline Sum & & 6.510 & 6.687 & 6.669 & 6.678 & 6.660 \\
\hline
\end{tabular}

\footnotetext{
${ }^{14}$ Profit and surpluses are in billion euros.
} 
Table 5: Simulations results ${ }^{15}$ with universal service fund

\begin{tabular}{|c|c|c|c|c|c|c|}
\hline & & \multicolumn{5}{|c|}{ Competition - Ramsey } \\
\hline & & \multicolumn{4}{|c|}{ Bypass } & \multirow{2}{*}{$\frac{\text { No Bypass }}{>0.06}$} \\
\hline$\tau:$ & & 0 & 0.01 & 0.03 & 0.05 & \\
\hline \multicolumn{7}{|l|}{ Prices: } \\
\hline -single-piece & $\mathbf{q}$ & 0.853 & 0.821 & 0.762 & 0.710 & 0.608 \\
\hline \multirow[t]{2}{*}{-USP bulk } & $\mathbf{p}_{U}^{I}$ & 0.287 & 0.294 & 0.308 & 0.323 & 0.359 \\
\hline & $\mathbf{p}_{R}^{I}$ & 0.538 & 0.523 & 0.496 & 0.471 & 0.424 \\
\hline \multirow[t]{2}{*}{-access } & $\mathbf{a}_{U}$ & - & - & - & - & 0.210 \\
\hline & $\mathbf{a}_{R}$ & 0.357 & 0.335 & 0.294 & 0.256 & 0.269 \\
\hline \multirow[t]{2}{*}{-entrants } & $\mathbf{p}_{U}^{E}$ & 0.300 & 0.310 & 0.330 & 0.350 & 0.360 \\
\hline & $\mathbf{p}_{R}^{E}$ & 0.507 & 0.485 & 0.474 & 0.456 & 0.419 \\
\hline \multicolumn{7}{|l|}{ Quantities: } \\
\hline \multirow[t]{3}{*}{-single-piece } & $\mathbf{x}_{U}$ & 1.374 & 1.395 & 1.432 & 1.466 & 1.531 \\
\hline & $\mathbf{x}_{R}$ & 0.344 & 0.349 & 0.358 & 0.366 & 0.383 \\
\hline & Total & 1.718 & 1.743 & 1.790 & 1.832 & 1.914 \\
\hline \multirow[t]{3}{*}{-USP bulk } & $\mathbf{y}_{U}^{I}$ & 6.221 & 6.314 & 6.485 & 6.637 & 5.909 \\
\hline & $\mathbf{y}_{R}^{I}$ & 1.370 & 1.315 & 1.428 & 1.462 & 1.526 \\
\hline & Total & 7.591 & 7.629 & 7.913 & 8.098 & 7.435 \\
\hline \multicolumn{2}{|c|}{ Total USP volumes } & 9.308 & 9.373 & 9.703 & 9.931 & 9.349 \\
\hline \multirow[t]{3}{*}{-Entrant's bulk } & $\mathbf{y}_{U}^{E}$ & 1.142 & 0.957 & 0.603 & 0.269 & 0.922 \\
\hline & $\mathbf{y}_{R}^{E}$ & 0.116 & 0.219 & 0.121 & 0.124 & 0.130 \\
\hline & Total & 1.258 & 1.176 & 0.725 & 0.393 & 1.052 \\
\hline \multicolumn{2}{|c|}{ Total market volumes } & 10.567 & 10.548 & 10.428 & 10.324 & 10.401 \\
\hline
\end{tabular}

${ }^{15}$ Prices are in euros and volumes in billion items. 
Table 5 (continued): Simulations results ${ }^{16}$ with US fund

\begin{tabular}{|c|c|c|c|c|c|c|}
\hline & & \multicolumn{5}{|c|}{ Competition - GPC } \\
\hline & & \multicolumn{4}{|c|}{ Bypass } & \multirow{2}{*}{$\begin{array}{c}\text { No Bypass } \\
>0.06\end{array}$} \\
\hline$\tau$ & & 0 & 0.01 & 0.03 & 0.05 & \\
\hline \multicolumn{7}{|c|}{ Contributions to Profit } \\
\hline \multirow[t]{2}{*}{-single-piece } & urban & 0.774 & 0.740 & 0.676 & 0.615 & 0.487 \\
\hline & rural & 0.176 & 0.168 & 0.151 & 0.135 & 0.103 \\
\hline \multirow[t]{2}{*}{-USP's bulk } & urban & 0.354 & 0.402 & 0.507 & 0.619 & 0.765 \\
\hline & rural & 0.354 & 0.320 & 0.308 & 0.279 & 0.219 \\
\hline \multirow[t]{2}{*}{-Access } & urban & - & - & - & - & access + tax $=0.092$ \\
\hline & rural & 0.023 & 0.038 & 0.016 & 0.012 & access $+\operatorname{tax}=0.014$ \\
\hline \multirow[t]{2}{*}{- Tax } & urban & - & 0.010 & 0.018 & 0.013 & \\
\hline & rural & - & 0.002 & 0.004 & 0.006 & \\
\hline \multicolumn{2}{|c|}{ Share of single-piece } & 0.565 & 0.541 & 0.492 & 0.447 & 0.351 \\
\hline \multicolumn{2}{|c|}{ Share of Access } & 0.014 & 0.023 & 0.010 & 0.007 & access + tax $=0.063$ \\
\hline \multicolumn{2}{|c|}{ Share of Tax } & 0 & 0.007 & 0.013 & 0.012 & \\
\hline \multicolumn{7}{|c|}{ Net User Surpluses } \\
\hline \multirow[t]{2}{*}{-single-piece } & urban & 1.475 & 1.520 & 1.603 & 1.679 & 1.831 \\
\hline & rural & 0.369 & 0.380 & 0.401 & 0.420 & 0.458 \\
\hline \multirow[t]{2}{*}{-bulk } & urban & 3.832 & 3.778 & 3.671 & 3.563 & 3.330 \\
\hline & rural & 0.731 & 0.754 & 0.794 & 0.832 & 0.907 \\
\hline Sum & & 6.407 & 6.432 & 6.468 & 6.493 & 6.526 \\
\hline
\end{tabular}

\footnotetext{
${ }^{16}$ Profit and surpluses are in billion euros.
} 


\section{Appendix}

We show how to decentralize the Ramsey second-best optimal prices with a minimum margin constraint (section 3.1.) using a global price cap. With a global price cap, the USP maximizes its profit subject to the constraint that an average of its prices cannot exceed a certain level, which we call the price cap. The regulator sets both the price cap and the weights to be used by the USP when calculating its average price. The USP then optimizes by choosing the level of its individual prices.

Assume for the moment that the regulator has chosen the following weights: $n_{x}$ for single-piece price, $n_{i}^{I}$ for bulk mail in area $i$ and $n_{a i}$ for access charge to area $i$, as well as the average price of $\bar{p}$. The optimization program of the USP is then

$$
\begin{aligned}
& \max _{q, p_{U}^{I}, p_{R}^{I}, a_{U}, a_{R}}\left(q-c_{x}-d_{x U}\right) x_{U}+\left(q-c_{x}-d_{x R}\right) x_{R} \\
& +\left(p_{U}^{I}-c^{I}-d_{U}^{I}\right) y_{U}^{I}+\left(p_{R}^{I}-c^{I}-d_{R}^{I}\right) y_{R}^{I} \\
& +\left(a_{U}-d_{U}^{I}\right) y_{U}^{E}+\left(a_{R}-d_{R}^{I}\right) y_{R}^{E}-F \\
& -\mu\left[n_{x} q+n_{U}^{I} p_{U}^{I}+n_{R}^{I} p_{R}^{I}+n_{a U} a_{U}+n_{a R} a_{R}-\bar{p}\right]
\end{aligned}
$$

where $\mu$ denotes the Lagrange multiplier of the price cap constraint and where the arguments of the demand functions have been omitted. We add to this classical GPC the margin constraints (2) and denote by $\zeta_{i}$ the Lagrange multiplier for the margin constraint in area $i$. The first order condition for $q$ is given by

$$
x_{U}+x_{R}+\left(q-c_{x}-d_{x U}\right) \frac{\partial x_{U}}{\partial q}+\left(q-c-d_{x R}\right) \frac{\partial x_{R}}{\partial q}-\mu n_{x}=0,
$$

while the first-order conditions for bulk mail prices and access charges are given by

$$
\begin{gathered}
y_{i}^{I}+\left(p_{i}^{I}-c^{I}-d_{i}^{I}\right) \frac{\partial y_{i}^{I}}{\partial p_{i}^{I}}+\left(a_{i}-d_{i}^{I}\right) \frac{\partial y_{i}^{E}}{\partial p_{i}^{I}}-\mu n_{i}^{I}+\zeta_{i}=0 \\
y_{i}^{E}+\left(p_{i}^{I}-c^{I}-d_{i}^{I}\right) \frac{\partial y_{i}^{I}}{\partial p_{i}^{E}}+\left(a_{i}-d_{i}^{I}\right) \frac{\partial y_{i}^{E}}{\partial p_{i}^{E}}-\mu n_{a i}-\zeta_{i}=0 .
\end{gathered}
$$

We denote the prices solving the modified Ramsey problem (equations (3), (4) and (5)) with a star: $q^{*}, p_{i}^{I *}$ and $a_{i}^{*}, i=U, R$. The decentralization of these prices requires that there exist values $\mu^{*}$ and $\zeta_{i}^{*}$ of the Lagrange multipliers such that $\left(q^{*}, p_{i}^{I *}, a_{i}^{*}, \mu^{*}, \eta_{i}^{*}\right)$ solve (15),(16) and (17). For this, the values of the weights and of the price cap must be chosen carefully by the regulator. Comparing the first order conditions of the modified Ramsey 
problem and of the GPC with margin constraints, one can show that the weights should be set equal to the corresponding third-best quantities,

$$
\begin{aligned}
n_{x}^{*} & =x_{U}\left(q^{*}\right)+x_{R}\left(q^{*}\right), \\
n_{i}^{I *} & =y_{i}^{I}\left(p_{i}^{I *}, c^{E}+a_{i}^{*}\right), \\
n_{a i}^{*} & =y_{i}^{E}\left(p_{i}^{I *}, c^{E}+a_{i}^{*}\right),
\end{aligned}
$$

and the average price to the corresponding average

$$
\bar{p}^{*}=n_{x}^{*} q^{*}+n_{U}^{I *} p_{U}^{I *}+n_{R}^{I *} p_{R}^{I *}+n_{a U}^{*} a_{U}^{*}+n_{a R}^{*} a_{R}^{*} .
$$

One can verify that the Lagrange multipliers of the price-cap constraint and of the minimum margin constraints are given by

$$
\begin{aligned}
\mu^{*} & =\frac{1}{1+\lambda^{*}}, \\
\zeta_{i}^{*} & =\frac{\eta_{i}^{*}}{1+\lambda^{*}},
\end{aligned}
$$

where $\lambda^{*}$ (resp. $\eta_{i}^{*}$ ) is the optimal value of the Lagrange multiplier of the budget constraint (resp., of the minimum margin constraint in area $i$ ) in the modified Ramsey problem.

In words, the decentralisation properties of the GPC still hold when an (arbitrary) constraint is imposed on the Ramsey problem. This generalizes the decentralization results developed for a generic network industry in Laffont and Tirole (1996) and applied to the postal sector by Crew and Kleindorfer (1995) and Billette et al. (2003). 